\title{
A ciência nos perfumes: atribuindo significados a Química Orgânica através da história da temática
}

\author{
Márcia Maria Pinto Coelho \\ Marlon Duarte Moreira \\ Andréia Francisco Afonso
}

\section{Resumo}

O aprendizado de Química Orgânica, geralmente, está associado à memorização de fórmulas, nomes e estruturas das moléculas. Muitos discentes apresentam dificuldade na aprendizagem das funções orgânicas, não conseguindo classifica-las a partir das suas especificidades. Consequentemente, não conseguem reconhecer situações e produtos empregados no cotidiano, cuja composição contém compostos orgânicos. Baseados nessas premissas, e buscando um ensino de Química Orgânica que contemplasse todas essas questões, elaboramos uma sequência didática desenvolvida em quatro aulas com a temática Perfume, junto ao terceiro ano do Ensino Médio de uma escola estadual de Juiz de Fora, parceira do subprojeto Química do Programa Institucional de Bolsa de Iniciação à Docência da Universidade Federal de Juiz de Fora. A primeira aula teve início com a explicação da origem da palavra Perfume, e como novos aromas foram descobertos a partir da queima de materiais orgânicos e de técnicas e equipamentos científicos, estabelecendo um paralelo com a produção de perfumes nos dias de hoje. Discutimos as diversas utilidades das fragrâncias produzidas pelas civilizações, como, por exemplo, servir de oferenda a deuses. Assim, ao longo dos séculos, os aromas foram incorporados aos costumes da sociedade. $\mathrm{Na}$ segunda aula, apresentamos trechos do filme "Perfume - a história de um assassino", tendo como foco o desenvolvimento da Ciência em relação às técnicas de extração dos óleos essenciais em diferentes épocas da História, desde o século XVIII. E, para finalizar, disponibilizamos seis amostras: água potável, álcool hidratado, óleo de girassol, vinagre, essência de cravo e perfume de limão e patchouli para que os alunos as identificassem a partir da fragrância exalada. Todas as lembranças remetidas a elas foram registradas em uma folha. As fórmulas estruturais das moléculas de cada amostra foram escritas no quadro para que pudéssemos retomar a explicação das funções orgânicas. Finalizamos a sequência didática descrevendo como as células olfativas captam as moléculas que compõem o aroma e chegam ao cérebro para que esse seja reconhecido e forme a memória olfativa. A partir das observações registradas no diário de campo dos bolsistas de iniciação à docência, verificamos que a curiosidade dos estudantes foi instigada desde o início. 0 interesse foi demonstrado através dos questionamentos e do empenho para desenvolver as tarefas propostas. Houve discussão sobre questões de gênero, não previstas durante o planejamento das aulas, mas que foram importantes para o esclarecimento de algumas questões que emergiram. Portanto, acreditamos que um ensino que proporcione uma abordagem mais ampla seja um dos caminhos para obtermos a qualidade tão desejada na educação.

Palavras-chave: Química Orgânica; Perfume; História da Ciência.

\begin{abstract}
The learning of Organic Chemistry is usually associated with the memorization of formulas, names and structures of organic molecules. Many students have difficulty to learn organic functions; they are not able to classify them from their specificities. Consequently, they cannot recognize situations and products used in daily life, whose composition contains organic compounds. Based on these premises and looking for a teaching of Organic Chemistry that contemplated all these questions, we elaborated a didactic sequence, developed in four classes, with the theme Scent. We developed it with the third year of High School of Juiz de Fora, partner of the Chemical subproject of the Institutional Program of the Initiation to Teaching Scholarship of the Federal University of Juiz de Fora. The first class began with the explanation of the origin the word scent, and how new aromas were discovered from the burning of organic materials and scientific techniques and equipment, establishing a parallel with the production of scents currently. We discuss the various uses of fragrances produced by civilizations, such as serving as an offering to gods. Thus, over the centuries, the society incorporated the aromas into her customs. In the second class, we present excerpts from the film "Perfume - the story of a murderer", focusing on the development
\end{abstract}


of science in relation to the techniques of extraction of essential oils at different times in History since century XVIII. To conclude, we offer six samples: drinking water, hydrated alcohol, sunflower oil, vinegar, clove essence and lemon scent and patchouli for students to identify from the exhaled fragrance. The students wrote all the memories sent to them on a sheet. We wrote the structural formulas of the molecules of each sample on the board and so that we could return to the explanation of organic functions. We finish the didactic sequence, describing how the olfactory cells capture the molecules that make up the aroma and reach the brain, that recognize it and forms the olfactory memory. From the observations recorded in the field diary of the scholarships, we realized that the curiosity of the students was instigated from the beginning. The questions demonstrated the students' interest through the questions and commitment to develop the proposed tasks. There was discussion on genre issues, not foreseen during class planning but important for clarifying some of the issues that emerged. Therefore, we believe that teaching that provides a broader approach is one way of achieving the desired quality of education.

Keywords: Organic Chemistry; Scent; Science History.

\section{INTRODUÇÃO}

A Química Orgânica é uma das especialidades da Química. Ao longo dos anos, o entendimento do objeto de estudo da área foi debatido e

Durante muito tempo, a Química Orgânica foi considerada como a Química dos produtos naturais de origem animal e vegetal, derivando daí seu nome. Podemos dizer que a definição mais frequente para a Química Orgânica é a que conceitua essa área como o ramo da Química que trata dos compostos de carbono. ${ }^{1}$

$\mathrm{Na}$ Educação Básica, seu aprendizado, geralmente, está associado à memorização de fórmulas e nomes das diferentes estruturas orgânicas, o que desestimula o estudo, pois a aprendizagem se torna mecanizada e bem distante da realidade vivenciada pelos estudantes. $E$ quando os alunos não conseguem identificar os conteúdos químicos em situações do cotidiano, a importância atribuída a eles é reduzida, uma vez que não é possível identificar os objetivos a que se propõe o ensino da disciplina. Por exemplo, nos últimos anos, muito se fala e ouve sobre fertilizantes orgânicos, alimentos orgânicos e horta orgânica, mas pouco é abordado sobre isso nas aulas de Química.

A linguagem científica também é pouco explorada e, portanto, algumas expressões próprias da Química Orgânica não conseguem ter uma representação adequada, o que sugere interpretações equivocadas. Um exemplo é o benzeno.

O aluno associa a molécula do benzeno, por exemplo, a um hexágono com uma bolinha dentro. Esta situação torna o estudo da química orgânica uma memorização de nomes e símbolos que, sem os devidos esclarecimentos, nada têm a ver com a

${ }^{1}$ M. S. Pazinato et al., "Uma Abordagem Diferenciada para o Ensino de Funções Orgânicas," Química Nova na Escola 34, nº 1 (2012): 21. 
realidade microscópica que eles representam. Da linguagem da química, aprende-se, quando muito, apenas os nomes das coisas, sem maior significado. ${ }^{2}$

De acordo com o trecho anterior, as representações e a linguagem passam a não possuir significado, tornam-se símbolos sem interpretação, e não códigos que transmitem uma informação. Logo, o estudante relaciona o benzeno a um composto de aroma agradável (composto aromático), estendendo esta qualidade às demais substâncias que o contém em sua estrutura. Contudo,

Nem toda substância aromática no sentido químico tem odor, para tal, sua molécula necessita ter, no máximo, em torno de vinte átomos de carbono e ser pouco polar, pois só assim é volátil, condição necessária para que sintamos o cheiro. ${ }^{3}$

E por não ter significado, a Química Orgânica não desperta o interesse dos alunos, que não conseguem identificar, classificar e diferenciar as funções orgânicas, o que, consequentemente, dificulta a compreensão da síntese das substâncias orgânicas que compõem diferentes produtos utilizados pela sociedade. Alguns desses produtos sintetizados estão sendo utilizados com diversas finalidades pelas civilizações ao longo da história. Os perfumes são um exemplo.

Entretanto, como as avaliações oficiais vêm apontando que os alunos do Ensino Médio apresentam dificuldade na aprendizagem de Química Orgânica, algumas propostas e ações vêm sendo implementadas a fim de buscar melhores resultados. Garcez \& Soares, ao realizarem um levantamento sobre a utilização do lúdico no ensino de Química, constatam que "o primeiro artigo foi publicado na Revista Química Nova em 1978 e trata-se de uma nota técnica apresentando um jogo de cartas como estratégia para o ensino de reações químicas na disciplina de Química Orgânica"4.

E no Ensino Médio,

Podemos perceber, na maioria dos livros didáticos e na fala de alguns professores, que a abordagem de grupos funcionais em Química Orgânica se baseia somente na identificação estrutural, de forma isolada, e na nomenclatura. ${ }^{5}$

\footnotetext{
2 N. F. Roque \& J. L. P. B. Silva, "A Linguagem Química e o Ensino da Química Orgânica," Química Nova 31, nº 4 (2008): 923.

${ }^{3}$ M. Lufti \& N. F. Roque, "Histórias de Eugênias," Química Nova na Escola 36, nº 4 (2014): 256.

${ }^{4}$ E. S. C. Garcez \& M. H. F. B. Soares, "Um Estudo do Estado da Arte Sobre a Utilização do Lúdico em Ensino de Química," Revista Brasileira de Pesquisa em Educação em Ciências 17, nº 1(2017): 191.

${ }^{5}$ C. O. B. Loyola \& F. C. Silva, "Plantas Medicinais: Uma Oficina Temática para o Ensino de Grupos Funcionais," Química Nova na Escola $39, \mathrm{n}^{0} 1(2017): 59$.
} 
As dificuldades não ficam restritas somente à Educação Básica. Elas prosseguem no ensino superior, principalmente para aqueles estudantes que ingressam nos cursos de Química - bacharelado ou licenciatura - nos quais a Química Orgânica é abordada de forma mais aprofundada. Assim, docentes e licenciandos, durante a prática pedagógica desenvolvida em situações de estágio supervisionado ou de iniciação à docência, buscam metodologias e recursos didáticos que facilitem o processo de ensino e aprendizagem de Química Orgânica. Entre eles, estão: os jogos, os modelos moleculares, as animações e mídias acessadas pelas tecnologias da informação. Através desses recursos é possível a visualização das estruturas moleculares e das funções orgânicas nelas presentes, na transposição do nível microscópico para o macroscópico.

O ensino de Química não pode ficar restrito à transmissão de informações com o auxílio do quadro e giz, esperando que os alunos compreendam todo o conteúdo da forma como gostaríamos. Entretanto, ao compararmos as aulas que são ministradas nas escolas de Educação Básica atualmente e em alguns anos atrás, percebemos que

[...] a abordagem química escolar continua praticamente a mesma. Embora às vezes maquiada com uma aparência de modernidade, a essência permanece a mesma, priorizando-se informações desligadas da realidade vivida pelos alunos e pelos professores. ${ }^{6}$

Contudo, não basta nos debruçarmos sobre uma metodologia que promova uma aula diferenciada e interessante aos estudantes. É preciso que eles percebam que o objeto de estudo faz parte do cotidiano, que é possível construir uma ponte ligando os saberes escolares a situações vivenciadas, nas quais os conhecimentos adquiridos no ambiente escolar podem ser essenciais para a resolução dos problemas enfrentados. Sendo assim, é necessário priorizar o processo de ensino e aprendizagem de uma forma mais contextualizada, propiciando um diálogo com os discentes e estimulando-os ao raciocínio para que percebam o quão importante a Química é para explicar os diferentes fenômenos do nosso cotidiano.

Mas para que a aprendizagem seja de fato significativa, consideramos que a participação ativa dos estudantes durante as atividades é fundamental, pois é através da reflexão e da tomada de decisão que os conhecimentos são construídos e mobilizados. Na recepção passiva de informações não é necessário qualquer esforço para entender as possíveis associações que podem ser estabelecidas entre os conceitos.

\footnotetext{
${ }^{6}$ Brasil, Ministério da Educação, Secretaria de Educação Básica, Parâmetros Curriculares Nacionais do Ensino Médio: Parte 3: Ciências da Natureza, Matemática e suas Tecnologias (Brasilia: MEC/SEB, 2000), 30.
} 
Por isso buscamos, na temática Perfume, desenvolver uma sequência didática que apresentasse não só conceitos da Química Orgânica, como também mostrar que a Química de uma maneira mais ampla faz parte dos diferentes fenômenos que acontecem ao nosso redor, sejam eles perceptíveis ou não.

Os aromas fazem parte da nossa vivência. A todo momento percebemos a fragrância exalada de um perfume, do tempero usado no preparo de alimentos, de uma flor, de algo em estado de decomposição, entre outros. Algumas vezes, o aroma nos alerta a termos atenção sobre algo que pode nos causar danos, como por exemplo, o cheiro de um alimento estragado, que além de ter sua cor alterada, exala um odor desagradável.

Além disso, temos que considerar que a Ciência que nos é apresentada vem de um contexto histórico. Foram muitos os desafios pelos quais os cientistas tiveram que superar para alcançar os resultados que, atualmente, facilitam nossas atividades diárias. Entre elas, podemos citar: a descoberta da lâmpada; a criação dos aparelhos tecnológicos, como celular e computadores; e a síntese de compostos orgânicos, que originam produtos utilizados diariamente. Mas esses resultados só vieram depois de inúmeras tentativas e algumas dificuldades, sejam elas relacionadas ao material para a realização dos experimentos; aceitação dos resultados obtidos pela comunidade científica; aquisição de novos conhecimentos, já que em séculos passados a comunicação não era tão rápida como atualmente. O conhecimento da Química, enquanto uma Ciência capaz de influenciar permanentemente na trajetória dos seres humanos e, consequentemente, na sua História, também ocorreu a partir de acasos, observações, até os estudos avançados. Nessa perspectiva, a História da Ciência auxilia na compreensão de como o conhecimento químico foi evoluindo ao longo dos séculos, mostrando-nos que as técnicas sofisticadas que temos atualmente, e que são utilizadas nos mais modernos laboratórios de pesquisa, foram aperfeiçoadas a partir de aparelhos que hoje consideramos rudimentares. Essa abordagem permite o reconhecimento da importância da Ciência, não só na área tecnológica, mais facilmente percebida, mas também em outros setores, como nas indústrias de fabricação de materiais para consumo. De acordo com Vieira \& Silva:

O mundo em que vivemos é produto das escolhas humanas do passado e as ações atuais estão inerentemente conectadas com o contexto histórico. A compreensão de fatores históricos é importante para a formação de indivíduos socialmente conscientes, reflexivos e críticos do seu papel no mundo. ${ }^{7}$

${ }^{7}$ C. A. Vieira \& A. F. Silva, "A História e a Química das Especiarias: Experiência de Aula Interdisciplinar para Estudantes do Ensino Médio," Revista Brasileira de Educação e Cultura, nº 16 (2017): 58. 
O trabalho dos autores mencionados anteriormente vai ao encontro da Base Nacional Comum Curricular, que indica como uma das competências de Ciências da Natureza no Ensino Fundamental, quando a disciplina é ministrada de forma integrada com a Biologia, a Física e Química: "Compreender as Ciências da Natureza como empreendimento humano, e o conhecimento científico como provisório, cultural e histórico"8.

Porém, a visão da Ciência como uma construção humana não é explorada pelos livros didáticos voltados para o Ensino Médio. E, assim, a realidade do ensino de Ciências, especificamente da Química, tem se voltado a uma apresentação dos conteúdos sem qualquer relação com o contexto histórico passado e atual. Pouco é descrito nos livros sobre a História das Ciências. Muitas vezes em um quadro em um dos cantos da página, há uma informação sobre o cientista descobridor da teoria que está sendo descrita no capítulo.

Sendo assim,

Diante do que foi exposto, percebe-se de forma coerente a importância de analisar os livros didáticos de Química antes de sua adoção. O livro selecionado pelo professor deve, antes de qualquer coisa, ser criterioso em relação às abordagens históricas apresentadas. $O$ livro não pode influenciar o seu leitor (aluno) a ter concepções errôneas ou falsas ideias sobre determinados acontecimentos. ${ }^{9}$

Baseado nessas premissas, este trabalho apresenta os resultados obtidos a partir de uma sequência didática desenvolvida a partir do tema Perfume, na qual buscamos a triangulação de três eixos: a Química Orgânica, a contextualização e a História da Ciência.

\section{Percurso metodológico}

A sequência didática a ser descrita a seguir foi desenvolvida no segundo bimestre de 2016 em quatro aulas de Química (com duração de 50 minutos cada uma), com uma turma do terceiro ano do Ensino Médio (totalizando 20 alunos) de uma escola da rede estadual de Minas Gerais, localizada na cidade de Juiz de Fora, parceira do subprojeto Química, integrante do Programa Institucional de Bolsa de Iniciação à Docência (PIBID) da Universidade Federal de Juiz de Fora.

A ideia para desenvolver a sequência didática com o tema Perfume se deu pelos seguintes motivos: ser algo do cotidiano da turma; os aromas terem diferentes finalidades que justifiquem o uso; despertar lembranças; possibilidade de apresentar a História da Ciência; e discutir conceitos pertinentes

\footnotetext{
${ }^{8}$ Brasil, Ministério da Educação, Base Nacional Comum Curricular (Brasília: MEC, 2017), 322.

${ }^{9}$ G. C. Mota \& M. G. Cleophas, "História da Ciência: Elaborando Critérios para Analisar a Temática nos Livros Didáticos de Química do Ensino Médio," História da Ciência e Ensino: Construindo Interfaces, $n^{0} 1$ (2015): 54.
} 
à Química Orgânica, já que compostos orgânicos são um dos assuntos previstos na matriz curricular do terceiro ano.

Na primeira aula, fizemos uma abordagem teórica sobre a origem da palavra Perfume: do latim Per, que significa origem de e Fumare - fumaça -, além de explicar como os aromas foram produzidos ao longo dos anos, a partir da queima de materiais orgânicos, e como os são atualmente. Neste momento, estabelecemos uma relação inicial com a Química Orgânica, buscando aproximar a disciplina de um contexto já conhecido pelos alunos.

Ainda procurando apresentar 0 assunto de forma contextualizada e baseada em um processo histórico, demos continuidade na exposição do tema. Contamos como os deuses eram homenageados com oferendas de fumaça proveniente da queima de madeira, folhas secas e animais, além de explicarmos a evolução no uso dos aromas, que foram gradualmente incorporados aos costumes da sociedade. Conforme menciona Dias \& Silva, 0

[...] passo seguinte na evolução do emprego dos aromas foi sua apropriação pelas pessoas, para o uso particular, algo que provavelmente aconteceu entre os egípcios. Um avanço posterior foi a descoberta de que certas flores e outros materiais vegetais e animais, quando imersos em gordura ou óleo, deixavam nestes uma parte de seu princípio odorífero. Assim eram fabricados os unguentos e os perfumes mencionados na Bíblia. ${ }^{10}$

Na semana posterior, realizamos a segunda aula, que ocorreu com a exibição de trechos do filme Perfume - a história de um assassino, produzido em 2006, com duração de 164 minutos, e adaptado do romance $\mathrm{O}$ Perfume, de Patrick Süskind. A história tem como cenário a França no século XVIII. O protagonista é o jovem Jean-Baptiste Grenouille, possuidor de um olfato extremamente apurado e, por isso, com uma grande habilidade para perceber diferentes odores. Ao longo do filme, o jovem busca amostras de aromas preciosos ainda não conhecidos por ele, que são extraídos dos corpos de mulheres jovens após a morte, e colocados em um decantador para a criação do óleo essencial que resultaria no perfume perfeito. Mas para conseguir obtê-lo, ele envolve-se em uma série de assassinatos.

Durante o desenrolar do drama são apresentados conceitos inerentes à Química que estão envolvidos na produção dos perfumes, assim como o processo de avanço da ciência em relação às técnicas de extração dos óleos essenciais - destilação e enfleurage - em diferentes épocas da História.

10 S. M. Dias \& R. R. Silva, "Perfumes," Química Nova na Escola, nº 4 (1996): 3. 
Acreditamos que o uso de filmes como estratégia de ensino pode agregar conhecimentos químicos importantes de uma forma diferenciada, propiciando uma discussão direcionada sobre o tema planejado para a aula. Segundo Santos \& Aquino,

[...] é fato que há uma grande quantidade de filmes comerciais que podem ser utilizados em disciplinas como História, Sociologia e Filosofia, mas ainda existe uma dificuldade em se escolher filmes e relacioná-los a temáticas específicas de Química, Física e Biologia. Filmes como dramas, comédias e suspenses podem ser utilizados para analisar a imagem de ciência e cientista, tendo seu conteúdo debatido em sala de aula. ${ }^{11}$

Entretanto, devido ao tempo destinado a aula, tivemos que realizar uma seleção prévia dos trechos do filme que foram exibidos aos estudantes. Os critérios de seleção se basearam em diferentes motivos que visavam contemplar os objetivos pré-estabelecidos no plano de aula:

- Cena do filme dos $11 \mathrm{~min} 05 \mathrm{~s}$ aos 12 min, que mostra o personagem Jean-Baptiste, ainda criança, tentando definir e nomear os cheiros ao seu redor, mesmo de olhos fechados - Instigar a reflexão e o desenvolvimento do pensamento científico dos discentes para que consigam obter uma explicação sobre como conseguimos perceber o cheiro de determinada substância e identifica-la a partir de suas características olfativas.

Com esta mesma cena também foi possível explicar como o nosso organismo reage ao cheiro, assunto esse retomado no terceiro momento.

- Cena do filme dos 49min 51s aos $51 \mathrm{~min} 17 \mathrm{~s}$, na qual Jean-Baptiste e seu mestre perfumista, Baldini, constroem um aparelho do tipo alambique para extrair uma onça (medida que corresponde a aproximadamente 29,57 mL) de óleo essencial a partir de 10 mil rosas - Abordar o processo de destilação para extração dos óleos essenciais a vapor e pela condensação no século XVIII. A partir das imagens, pudemos discutir e rever diferentes conceitos já estudados pelos alunos em etapas de escolarização anteriores, como estados físicos da matéria e suas mudanças, de acordo com fatores como temperatura e pressão.

${ }^{11}$ P. N. Santos \& K. A. S. Aquino, "Utilização do Cinema na Sala de Aula," Química Nova na Escola 33, n 3 (2011): 160. 
- Cena do filme de 1 h $09 \min 12$ s a 1 h 10 min 02s, que explica o processo de enfleurage desenvolvido em uma propriedade rural com vasta plantação de flores destinada a fabricação de perfumes. Com esta cena, conseguimos mostrar que é necessária uma grande quantidade de pétalas de rosas para se obter uma pequena quantidade de óleo essencial, que será usado na fabricação do perfume. Procuramos utilizar o termo óleos essenciais, nos apoiando no trabalho de Dias \& Silva:

[...] as fragrâncias características dos perfumes foram obtidas durante muito tempo exclusivamente a partir de óleos essenciais extraídos de flores, plantas, raízes e de alguns animais selvagens. Esses óleos receberam o nome de óleos essenciais porque continham a essência, ou seja, aquilo que confere à planta seu odor característico. ${ }^{12}$

- Cena do filme de $1 \mathrm{~h} 19 \mathrm{~min} 35 \mathrm{~s}$ a $1 \mathrm{~h} 20$ min 57s, quando Jean assassina uma mulher e a envolve em uma substância gordurosa para extrair o odor. Vale destacar que as cenas de violência não foram exibidas, ficando subentendido pelo diálogo apresentado pelos personagens que houve 0 assassinato. Nela, mostramos outra forma de extração que ocorreu por meio da afinidade química entre a gordura e as substâncias presentes no corpo da mulher.

Uma semana depois, no terceiro momento, com o uso de duas aulas seguidas (totalizando $1 \mathrm{~h}$ $40 \mathrm{~min}$ ), realizamos uma atividade dentro da própria sala. Levamos 18 tubos de ensaios numerados de 1 a 6 , com diferentes tipos de amostras: vinagre, álcool hidratado, água potável, colônia de limão e patchouli, óleo de girassol e essência de cravo. Havia 14 alunos presentes e, inicialmente, propusemos que cada um identificasse os aromas existentes, enquanto a professora e os dois bolsistas de iniciação à docência do PIBID acompanhavam os estudantes. Solicitamos que examinassem as amostras com tranquilidade e cuidado, de tal forma que pudessem perceber o aroma e associá-lo a alguma pessoa, local ou situação. Essas percepções foram registradas pelos estudantes em uma tabela impressa em folha de papel ofício, distribuída previamente no início da atividade. Tomamos como base o trabalho de Silva, Benites \& Soares para elaborarmos os objetivos dessa atividade. Segundo os autores,

A sensibilidade do sistema olfativo nos permite diferenciar odores agradáveis e desagradáveis. Essa diferenciação característica é evidenciada pelo comportamento do sujeito que, dependendo do odor ou aroma identificado, poderá sentir-se envolvido

12 Dias \& Silva, "Perfumes," 4. 
em uma sensação prazerosa ou, então, em uma sensação desagradável, desconfortante. ${ }^{13}$

Após os alunos completarem a tabela, revelamos a natureza das amostras de cada tubo para que eles comparassem com os registros feitos. E pedimos que cada um se expressasse oralmente sobre o que tinha escrito.

As observações realizadas durante todas as aulas, assim como os comentários e dúvidas dos alunos, foram registradas nos diários de campos pelos dois bolsistas de iniciação à docência e pela professora supervisora. Os diários permitem que os registros sejam revistos a qualquer momento, o que pode proporcionar, a cada leitura, um olhar diferente sobre as situações pesquisadas. ${ }^{14}$

Finalizamos a atividade escrevendo no quadro as fórmulas estruturais do ácido etanóico, contido no vinagre; do etanol e do ácido cítrico, presente no limão; e do eugenol, que é a substância com maior teor na essência do cravo. A escolha do eugenol teve como aporte o trabalho de Lufti \& Roque, ao descreverem que

Os químicos conseguiram separar, da mistura complexa que forma o óleo essencial do cravo-da-índia, as substâncias predominantes. Aquela que ocorre em maior quantidade foi denominada eugenol, por ter sido obtida de uma espécie do gênero Eugenia. ${ }^{15}$

A partir delas, identificamos as diferentes funções orgânicas existentes nas estruturas, reforçando a percepção de existência delas em substâncias presentes no cotidiano.

\section{RESULTADOS E DISCUSSÃo}

Percebemos que o interesse pelas aulas foi despertado desde o momento que apresentamos a origem da palavra perfume. O latim não é mais utilizado e ensinado nas escolas, porém, as palavras que hoje utilizamos e aprendemos, especialmente nas aulas de Língua Portuguesa, têm origem nele. Ao perceber a associação das palavras escritas em latim e seus significados, os alunos conseguiram associar e compreender a ortografia de palavras de nossa língua.

Utilizamos a definição de Lima, Silva \& Tonin para trabalharmos a temática. De acordo com os autores, os

\footnotetext{
13 V. A. Silva, A. M. C. Benite, \& M. H. F. Soares, "Algo Aqui Não Cheira Bem...," Química Nova na Escola 33, no 1 (2011): 4.

${ }^{14}$ E. Marandola Jr., F. C. Paula, \& M. C. S. Pires, "Diários de Campo: Aproximações Metodológicas a Partir da Experiência Metropolitana (Campinas e Santos)," in Novas Metrópoles Paulistas, org. J. M. P. Cunha, $459-491$ (Campinas: Nepo/Unicampo, 2006).

${ }^{15}$ M. Lufti \& N. F. Roque, "Histórias de Eugênias," Química Nova na Escola 36, nº 4 (2014): 256.
} 
Perfumes são soluções que contêm substâncias aromatizadas de odor agradável, na forma de misturas destas fragrâncias dissolvidas em um solvente, geralmente o etanol que, por sua vez, contém uma pequena quantidade de água. ${ }^{16}$

A partir da abordagem de como o perfume vem sendo utilizado ao longo da História, mantivemos a atenção dos estudantes para aula. Apesar de ser usado por muitos deles, os alunos não tinham o conhecimento das finalidades atribuídas aos aromas pelas antigas civilizações, e que estão ligadas à questões religiosas e científicas, havendo uma breve comparação com o uso feito pela sociedade atual. Normalmente, o perfume remete a poder e sensualidade, devido às marcas famosas que dão seus nomes a fragrâncias comercializadas a preços não acessíveis para todos. A curiosidade dos estudantes continuou a ser instigada com a apresentação do filme, nas cenas que mostravam como a ciência era desenvolvida no século XVIII. Houve questionamentos no sentido de compreender o processo do uso de compostos orgânicos na fabricação dos perfumes. As propagandas de divulgação desses produtos anunciam a presença de substâncias diferenciadas na composição dos aromas, mas as etapas para obtenção dos mesmos, que se tornam um diferencial da empresa fabricante, são guardadas confidencialmente. Sabemos apenas que nos perfumes são adicionados fixadores e propilenoglicol. 0 primeiro para retardar a evaporação da essência e o segundo, com o intuito de aumentar a solubilidade do "óleo" (essência)"17.

A partir dessa discussão, os alunos puderam expressar suas preferências em relação aos aromas, sendo constatado, ao final, que o julgamento - bom ou ruim, forte ou fraco - é individual. Nesse momento, aproveitamos para expor questões, como o respeito pelo outro, independente das divergências de opinião ou gosto. A partir das falas dos estudantes, pudemos conhecer suas preferências em relação aos perfumes.

O conhecimento da turma é fundamental para que consigamos estreitar as relações interpessoais e planejarmos as aulas, de modo a atender as especificidades e, assim, obtermos um bom desempenho no processo de ensino e aprendizagem nas aulas de Química. É preciso dar voz aos discentes para que eles nos direcionem sobre o melhor meio de conduzir as aulas. Não só as preferências, mas também as vivências relacionadas aos aromas puderam ser trabalhadas na atividade das últimas aulas. Foi um momento que os alunos se sentiram à vontade para expor situações relacionadas à vida familiar e afetiva que os afligiam ou que os remetiam a momentos alegres. São elas,

\footnotetext{
16 M. A. Lima, A. C. R. Silva, \& L. T. D. Tonin, "Perfumes: Uma Proposta de Contextualização para o Ensino de Química," https://dspace.unila.edu.br/bitstream/handle/123456789/3098/PIBID1\%2c1929-1932.pdf?sequence=1\&isAllowed=y (acessado em 27 de janeiro de 2018), 1928-29.

17 Lima, Silva, \& Tonin, "Perfumes: Uma Proposta de Contextualização," 1929.
} 
e os sentimentos que dela afloram, um dos fatores que influenciam - positivamente ou negativamente na aprendizagem. Os resultados estão descritos para cada amostra:

- Amostra 1: Todos os alunos reconheceram que era vinagre, o que revela ser uma substância facilmente reconhecida e do cotidiano dos alunos, sendo utilizada no tempero e higienização dos alimentos. A análise desse dado vai ao encontro da pesquisa de Nascimento, Ribeiro \& Batista, no qual investigaram a percepção sensorial de alunas do curso de Pós-Graduação em Nutrição.

Os resultados mostraram que os maiores índices de acertos foram verificados para os aromas das amostras de limão (84\%), café $(80 \%)$, canela (80\%), cravo $(80 \%)$ e vinagre (80\%); e que a pimenta calabresa e o coentro não foram reconhecidos por nenhum provador. ${ }^{18}$

- Amostra 2: Apesar de ter um odor característico, 64\% afirmaram ser álcool hidratado, enquanto $22 \%$ a associaram à cola, $7 \%$ a cheiro de hospital e outros $7 \%$ a exame de sangue. Nesta amostra, os discentes, apesar de não lembrarem o nome da substância, recordaram do ambiente e de uma situação na qual se faz uso de álcool hidratado.

- Amostra 3: 85,7\% registraram o termo correto - água potável -, o restante usou os termos podre e cheiro desconhecido. Não houve uma justificativa para o registro da palavra podre, somente para cheiro desconhecido. Como a amostra não exalava um aroma, os estudantes não conseguiram identificá-la, apesar de, já desde os primeiros anos de escolarização, definirem a água potável como uma substância incolor, insípida e inodora. A água para eles está associada ao que consomem e que, geralmente, apresenta o cheiro do cloro, que é adicionado pelas empresas de tratamento e saneamento para a higienização da mesma.

- Amostra 4: Ela consistia de uma pequena quantidade de uma colônia produzida por marca famosa e comercializada com o nome Águas de limão e Patchouli. O fabricante a descreve como uma mistura das notas frescas e vibrantes do limão com o amadeirado do patchouli, considerada uma fragrância feminina exótica.

Como seria difícil para os alunos reconhecerem o nome do perfume, eles classificaram a amostra em feminino e masculino e pela composição - componentes que acreditavam existir no perfume -, além

${ }^{18}$ K. O. Nascimento, D. F. Ribeiro, \& E. Batista, "Reconhecimento de Aromas e Aplicação de Testes Afetivos como Forma de Aprendizado," e-xacta 7, n 1 (2014): 139. 
de citarem as lembranças que lhes vieram à mente, quando perceberam o aroma. As respostas estão na Tabela 1.

Tabela 1: Porcentagem das respostas relacionadas a amostra $4 .{ }^{19}$

\begin{tabular}{|c|c|c|c|}
\hline GÊNERO & COMPOSIÇÃO & LEMBRANÇAS & $\%$ RESPOSTAS \\
\hline Masculino & & & $29 \%$ \\
\hline Feminino & & & $22 \%$ \\
\hline & Amadeirada & & $14 \%$ \\
\hline & & Cheiro do pai & $7 \%$ \\
\hline & & Produtos de limpeza & $7 \%$ \\
\hline & Flores - Rosas & & $21 \%$ \\
\hline
\end{tabular}

As questões de gênero foram mencionadas, como mostra a Tabela 1, o que gerou uma ampla discussão. Assim, voltando à questão do respeito, já discutida na aula anterior, já que a preferência por um ou outro aroma é pessoal, independentemente do gênero, apesar dos perfumes serem classificados em feminino e masculino. De acordo com Teixeira, Marques \& Martins, "a publicidade a perfumes é das mais ousadas na utilização de imagens e cenas de conteúdo sexista"20, o que nos leva a classificar um perfume como feminino ou masculino.

A memória afetiva, assim como a associação de algo de uso cotidiano, foi estimulada. Nesse momento, retomamos a discussão de como os aromas estão associados em nossa memória com situações vivenciadas e que foram marcantes de alguma forma para nós. Um aroma pode nos trazer um sentimento de alegria ou tristeza, pois ele está associado a uma situação passada que pode ter sido um momento bom ou ruim.

Deve-se salientar que nossa estrutura cognitiva tem facilidade de guardar lembranças relacionadas ao mau cheiro. Por mais que os cheiros agradáveis nos façam melhores e nos extasiem mais, é o mau cheiro que efetivamente desperta caminhos. ${ }^{21}$

- Amostra 5: 0 óleo de girassol foi reconhecido por apenas 21,42\%. A palavra fezes foi mencionada por $14,28 \%$, e para $64,31 \%$, era canela, alecrim e outra substância adocicada. A pequena quantidade de alunos que reconheceram o óleo de girassol se deu por não ser esta uma substância de uso comum pela turma.

\footnotetext{
${ }^{19}$ Elaborada pelos autores.

20 F. Teixeira, F. M. Marques, \& I. P. Martins, "Sexualidade e Género no Discurso Publicitário: Implicações Educacionais," http://blogs.ua.pt/isabelpmartins/bibliografia/Atas_Int_37_

sexualidade\%20e\%20genero_2008.pdf (acesso em 27 de janeiro de 2018), 10.

${ }^{21}$ Silva, Benite, \& Soares, "Algo Aqui Não Cheira Bem...," 7.
} 
- Amostra 6: A essência de cravo foi associada a um perfume masculino por $36 \%$, e por outros $36 \%$ a um perfume feminino. Outros termos mencionados: cheiro de terra, perfume forte, álcool, amadeirado, sendo cada um deles, associados por 7\%. Os dados nos mostram que os estudantes conseguiram relacionar a amostra aos perfumes, já que a essência de cravo é uma substância que compõem alguns perfumes comercializados, e que, provavelmente, fazem uso.

A investigação do conteúdo das amostras possibilitou aos discentes o estudo dos compostos orgânicos e sua associação com o tema abordado, além da compreensão de como o olfato reconhece um perfume através de uma explicação baseada em conhecimentos químicos.

Presenciamos momentos de curiosidade, confrontos de opiniões e variadas observações, todos ocorridos em virtude das sensações trazidas pelos aromas, fato este que encontra justificativa no trabalho de Vidal \& Melo,

Estudar o ser humano é sempre desafiador, ainda mais quando se trata de algo tão subjetivo quanto às sensações. Elas fazem parte da nossa vida e nos tornam seres particularmente únicos. Esse assunto se torna mais desafiador quando se tenta inserilo no ensino da disciplina de química para o ensino médio, pois os alunos ainda não têm conhecimento adquirido sobre os diversos tipos e as funções das substâncias químicas. $^{22}$

O trecho anterior confirma a importância da abordagem de temas como o que foi escolhido para o desenvolvimento deste trabalho - Perfume.

\section{CONSIDERAÇÕES FINAIS}

A sequência didática propiciou a abordagem da Química Orgânica de forma mais dinâmica e contextualizada, já que foram utilizadas diferentes metodologias que propiciaram a participação ativa dos estudantes, fazendo-os refletir e expor suas ideias a partir de argumentos estruturados e apoiados nos saberes escolares que estavam sendo construídos.

A identificação das funções orgânicas em moléculas de substâncias conhecidas permitiu uma aproximação da Química com o contexto real, desmistificando a concepção de que a área está envolvida somente em situações que causam danos ao meio ambiente e aos seres humanos.

${ }^{22}$ R. M. B Vidal \& R. C. Melo, "A Química dos Sentidos: Uma Proposta Metodológica," Química Nova na Escola 35, nº 1 (2013): 183. 
Ao identificarem nas substâncias de uso cotidiano as moléculas orgânicas, houve o estímulo da curiosidade e o interesse para o aprendizado mais aprofundado, na busca de estabelecer relações entre os diferentes conceitos que foram apresentados durante a sequência didática.

$O$ resgate histórico da utilização dos perfumes e da metodologia científica exibida no filme fez com que os estudantes compreendessem como a Ciência avança ao longo dos anos, através de experimentos e equipamentos utilizados em laboratórios e que permitem 0 avanço do conhecimento científico. As imagens auxiliaram na percepção de que o conhecimento científico é produzido por mulheres e homens que se voltam a solucionar um problema, através de estudos e experimentos. E para 0 alcance dos resultados são necessárias inúmeras tentativas.

Além de aproximar os saberes escolares da realidade dos estudantes, a apresentação da temática Perfume permitiu a valorização dos conhecimentos prévios, ou seja, daqueles adquiridos em outros contextos fora da escola. Eles são importantes na medida que podem, muitas vezes, constituíremse como aportes para a construção dos novos conhecimentos.

\section{SOBRE OS AUTORES:}

Márcia Maria Pinto Coelho

Escola Estadual Duarte de Abreu.

(e-mail: marciacoelhodiverso@hotmail.com)

\section{Marlon Duarte Moreira}

Universidade Federal de Juiz de Fora. Departamento de Química.

(e-mail: marlondmoreira@hotmail.com)

\section{Andréia Francisco Afonso}

Universidade Federal de Juiz de Fora. Departamento de Química.

(e-mail: andreia.afonso@ufjf.edu.br)

Artigo recebido em 30 de setembro de 2017 Aceito para publicação em 15 de fevereiro de 2018 